\title{
BIODIVERSIDADE: CONCEPÇÕES DE ALUNOS DO ENSINO MÉDIO EM QUEIMADAS-PB, BRASIL
}

\section{BIODIVERSITY: CONCEPTS OF HIGH SCHOOL STUDENTS IN QUEIMADAS-PB, BRAZIL}

\section{BIODIVERSIDAD: CONCEPTOS DE LOS ESTUDIANTES DE LA ESCUELA SECUNDARIA EN QUEIMADAS- PB, BRASIL}

\author{
Helder Neves de Albuquerque ${ }^{1}$
}

Joaci dos Santos Cerqueira ${ }^{2}$

1. Universidade Federal da Paraíba (UFCG). Programa de Pós-Graduação em Engenharia e Gestão de Recursos Naturais- PPGEGRN. Email: helderbiologo@gmail.com

2. Universidade Federal da Paraíba (UFCG). Programa de Pós-Graduação em Engenharia e Gestão de Recursos Naturais- PPGEGRN. Email: cerq2006@gmail.com

\begin{abstract}
RESUMO: O componente curricular Biologia permite aos estudantes conhecerem e avaliarem o seu ambiente natural, as diferentes comunidades existentes e as relações entre elas, obtendo assim o conhecimento do ecossistema. Assim, este estudo teve objetivos verificar as concepções de alunos do Ensino Médio em relação à biodiversidade. Para isso foi realizada uma pesquisa de campo, com abordagem quantitativa, através da aplicação de questionário entre março e junho de 2018, em uma escola de Ensino Médio da rede estadual em Queimadas PB, Brasil. Ficou evidente que os pesquisados detêm de algum conhecimento sobre a fauna, porém desconhecem a flora. Na concepção dos pesquisados relaciona o prejuízo da perda das espécies com a sua função e importância na natureza. Em relação aos meios de comunicações onde viram ou ouviram falar sobre o tema biodiversidade observou-se que a televisão se configurou como o principal meio de divulgação do tema. Desta forma, sugere-se que dentre os desafios para uma melhor abordagem educacional sobre o tema biodiversidade nas escolas de Queimadas-PB está à necessidade de conciliar o tema com os demais conteúdos obrigatórios da grade curricular, abordando as diversas variações locais. Portanto, o principal foco de abordagem do tema deve levar em

ABSTRACT: The Biology curricular component allows students to know and evaluate their natural environment, the different existing communities and the relationships between them, thus obtaining knowledge of the ecosystem. Thus, this study aimed to verify the conceptions of high school students in relation to biodiversity. For this purpose, a field research was carried out, with a quantitative approach, through the application of a questionnaire between March and June 2018, in a public high school in Queimadas - PB, Brazil. It was evident that those surveyed have some knowledge about the fauna, but are unaware of the flora. In the respondents conception, it relates the loss of species loss with its function and importance in nature. Regarding the media where they saw or heard about the topic of biodiversity, it was observed that television was configured as the main means of disseminating the topic. Thus, it is suggested that among the challenges for a better educational approach on the theme of biodiversity in the schools of Queimadas-PB is the need to reconcile the theme with the other mandatory contents of the curriculum, addressing the various local variations. Therefore, the main focus of approach to the theme must take regionalism into account.
\end{abstract} consideração o regionalismo.

Palavras-chave: Concepções, Educação Formal, Meio Ambiente, Preservação de Espécies.
Keywords: Conceptions. Formal Education. Environment. Preservation of Species.
RESÚMEN: El componente curricular de biología permite a los estudiantes conocer y evaluar su entorno natural, las diferentes comunidades existentes y las relaciones entre ellas, obteniendo así el conocimiento del ecosistema. Por lo tanto, este estudio tuvo como objetivo verificar las concepciones de los estudiantes de secundaria en relación con la biodiversidad. Para esto, se realizó una investigación de campo, con un enfoque cuantitativo, mediante la aplicación de un cuestionario entre marzo y junio de 2018 , en una escuela secundaria de la red estatal en Queimadas - PB, Brasil. Era evidente que los encuestados tienen algún conocimiento sobre la fauna, pero desconocen la flora. En la concepción de los encuestados, relaciona la pérdida de especies con su función e importancia en la naturaleza. En relación con los medios donde vieron o escucharon sobre el tema de la biodiversidad, se observó que la televisión se configuró como el principal medio para difundir el tema. Por lo tanto, se sugiere que entre los desafíos para un mejor enfoque educativo sobre el tema de la biodiversidad en las escuelas de Queimadas-PB está la necesidad de conciliar el tema con los otros contenidos obligatorios del plan de estudios, abordando las diversas variaciones locales. Por lo tanto, el enfoque principal del enfoque del tema debe tener en cuenta el regionalismo.

Palabras clave: Concepciones Educación Formal. Medio Ambiente. Preservación de Especies.

Recebido em: 15/02/2020

Aprovado em: 21/04/2020

Todo o conteúdo deste periódico está licenciado com uma licença Creative Commons (CC BY-NC-ND 4.0

Internacional), exceto onde está indicado o contrário. 


\section{Introdução}

O estudo da biodiversidade tem relação direta para a preservação/conservação das espécies, sendo de suma importância para o nosso desenvolvimento e continuidade das espécies, resultando no aproveitamento dos recursos biológicos para que sejam explorados de maneira menos prejudicial à natureza, conservando-a o máximo possível, permitindo a harmonia entre o desenvolvimento das atividades humanas e a manutenção da vida (ANDRADE; MONTEIRO, 2018).

A conservação da biodiversidade é essencial para que se possa garantir o equilíbrio ambiental em todos os ecossistemas. Sem isso o futuro da humanidade será incerto, fontes vitais de recursos também serão extintas e não haverá sustentação para a existência da vida em sua plenitude no futuro próximo. Portanto, devemos desenvolver métodos e ações ambientais e educacionais concretas para que ocorra uma conservação ambiental em sua plenitude e com desenvolvimento sustentável (SÖNCKSEN, 2017).

Em geral, os humanos não se dão conta de que as necessidades, os desejos de consumo, a exigência por determinados produtos, a mudança de hábitos alimentares, entre outros fatores são as causas da pressão sobre a biosfera, sem nenhum respeito à sua capacidade de suporte. Problemas ambientais tais como mudanças de clima, poluição das águas, do ar e dos alimentos costumam ter um apelo muito forte entre os habitantes das cidades, pois são questões que os afetam de forma direta. A perda da biodiversidade, porém, não incomoda grande parte da população, uma vez que as suas vidas parecem ser pouco alteradas em seu dia-a-dia (CENCI; BURMANN, 2013).

Falta percepção da sociedade sobre a necessidade de mudanças profundas nos processos produtivos, ainda baseados na exploração predatória dos recursos naturais (RATTNER, 2009). Há outros argumentos que explicam o problema, mas de forma geral, os especialistas concordam que a falta de priorização do tema por parte do poder público resulta em investimentos políticos, institucionais e financeiros incompatíveis com a relevância da questão (PEREIRA; DA SILVA; CARBONARI, 2017).

De acordo com Brasil (2006):

A discussão da biodiversidade e da codificação genética da vida, que ilustramos, para ganhar contexto e realidade deve ser associada aos problemas atuais da redução da biodiversidade, por conta das intervenções humanas na biosfera, decorrentes da industrialização, do desmatamento, da monocultura intensiva e da urbanização, assim como ser tratada juntamente com as questões atuais da manipulação genética e dos cultivos transgênicos (BRASIL, 2006, p. 30). 
Um projeto de educação ambiental tem por objetivo principal ampliar a visão de meio ambiente e saúde, para que os estudantes consigam compreender a complexidade das inter-relações que os caracterizam de forma reflexiva e problematizadora (PELICIONI, 2000).

As aulas de campo contribuem para os processos de ensino e de aprendizagem em educação ambiental, principalmente no que diz respeito à biodiversidade da fauna e da flora (MORAES et al., 2015). Pois, depois das aulas os alunos comentam o que eles acharam da biodiversidade e do Meio Ambiente, sendo desenvolvida uma atividade com o objetivo de coletar dados sobre a visão que os alunos possuem sobre estes temas (ROSSI; MANZANO, 2005; OLIVEIRA; CORREIA, 2015). Porém para se iniciar um trabalho na área de educação ambiental, é preciso começar fazendo com que os alunos expressem a leitura que fazem do ambiente em que vivem. Portanto, é necessário que se tomem providências urgentes no sentido de desenvolver em todos os cidadãos uma consciência ecológica, voltada para a criação de uma sociedade moderna (MEDEIROS, 2011; DEMOLY; SANTOS, 2018).

A conservação da biodiversidade é um tópico, dentro do próprio ensino de Ecologia, potencialmente capaz de suscitar discussão de valores e ética ambiental, incluindo aspectos utilitários e os essencialmente éticos (DINNEBIER, 2017). O estudo da biodiversidade, no entanto, não pode estar dissociado de todos os demais problemas ambientais e sociais. É necessário desenvolver mecanismos de integração das ações e dos objetivos mais gerais e abrangentes da educação e, em especial, da educação ambiental (FISCHER et al., 2017).

Atualmente é muito comum encontrarmos nas pesquisas educacionais estudos relacionados sobre o que pensam alunos e professores dentre as diversas áreas educacionais. Essa variedade de termos é usada se referindo, quase sempre, às representações mentais. Em nosso estudo utilizamos o termo Concepção, portanto, optamos por definir os mais usuais (concepção, percepção, representação e crença) para facilitar o entendimento do arcabouço teórico-conceitual desse estudo.

Em seus estudos Matos e Jardilino (2016), apresentam uma compilação dessas definições:

“As concepções podem informar a maneira como as pessoas percebem, avaliam e agem com relação a um determinado fenômeno" (p. 24).

A percepção é a "organização e interpretação de sensações/dados sensoriais" que resultam em uma "consciência de si e do meio ambiente", como uma "representação dos objetos externos/exteriores". (p. 25)

A representação pode ser definida como "qualquer imagem, pensamento, conteúdo formado no psiquismo que desempenhe o papel de algo". (p. 27) 
A crença é a “opinião, certeza não racional, assentimento sem prova e certeza sem prova”. (p. 26).

Diante da problemática de ensino que envolve os profissionais de Ciências, uma análise das concepções sobre biodiversidade no ambiente educacional fornece subsídios que justificam iniciativas pedagógicas que contribuam para sensibilização e conscientização sobre a importância da preservação e sobrevivência de espécies de animais e vegetais. Para isso, o objetivo geral desse estudo foi identificar as concepções de alunos do Ensino Médio sobre o tema biodiversidade em uma escola pública em Queimadas, Paraíba.

\section{Metodologia}

O presente trabalho foi desenvolvido com os alunos dos $1^{\circ}$ aos $3^{\circ}$ anos do Ensino Médio do turno vespertino em uma escola da rede pública da cidade de Queimadas-PB, Brasil, abordando a temática "concepções dos alunos do Ensino Médio sobre biodiversidade". A escola foi identificada através de um código, denominado $\mathrm{XY}$, a critério dos pesquisadores.

Portanto, diferentes trabalhos de pesquisa que exploram as ideias dos alunos ressaltam a íntima relação entre os termos conhecimentos, crenças e concepções. Nesse trabalho é importante ressaltar que foi considerado, da mesma forma que Moreno e Azcárate (2003) e Linares (2009) abordaram concepções como componentes do conhecimento, sendo que: concepções compreendidas como - organizadores implícitos dos conceitos, de natureza essencialmente cognitiva e que incluem crenças, significados, conceitos, proposições, regras, imagens mentais, preferências, dentre outros que influenciam no que se percebe e nos processos de argumentação e raciocínio que se realizam.

Este estudo foi realizado tomando por base metodológica a pesquisa quantitativa e estudo de caso. A amostragem totalizou 75 pesquisados distribuídos aleatoriamente entre 25 alunos de cada série ( $1^{\circ}, 2^{\circ}$ e $3^{\circ}$ anos $)$ do Ensino Médio na escola pesquisada.

A coleta de dados se deu através do questionário contendo questões abertas, aplicado pelos próprios pesquisadores, junto aos alunos dos $1^{\circ}$ aos $3^{\circ}$ anos do Ensino Médio no período de março e junho de 2018, nas respectivas salas de aula da própria unidade escolar. Desta maneira, buscou-se estabelecer um clima de empatia entre o pesquisador e os alunos participantes a fim de que estes pudessem se sentir livre para participar ou não do presente estudo, respeitando-se o Princípio da Autonomia. Antes do início da aplicação dos questionários foi explicado aos alunos o objetivo da pesquisa, apresentado o Termo de Esclarecimento e o Termo de Consentimento, a garantia do anonimato e da não relação com notas escolares. 
Para tanto, foram incluídos na pesquisa: a) Alunos(as) matriculados(as) e frequentando as aulas nas três turmas do Ensino Médio da Escola pesquisada, e; b) Alunos(as) que quiseram livremente participar do estudo.

Foram excluídos dessa pesquisa: a) Alunos(as) matriculados(as) em turmas que não eram foco da pesquisa; b) Os professores de ambos os gêneros que não eram foco da pesquisa; c) Alunos(as) que mesmo dentro dos critérios de inclusão não quiseram participar da pesquisa, e; d) Alunos(as) que mesmo dentro dos critérios de inclusão não devolverem os questionários respondidos.

O estudo das concepções pode ser abordado através da pesquisa qualitativa, capaz de incorporar a questão do significado e da intencionalidade como inerentes aos atos, às relações e às estruturas sociais, tomadas como construções humanas significativas. Os conflitos, as ideias, as crenças e os comportamentos presentes no campo social são expressos através da comunicação verbal. Assim, no método empregado utilizou-se como conjunto de instrumentos, as figuras metodológicas que viabilizam discriminar os principais temas das respostas apresentadas pelos alunos no que se refere ao presente objeto de estudo (TRIVIÑOS, 2009; MINAYO, 2014).

\section{Resultados e Discussão}

De acordo com o estudo foram sistematizados os resultados obtidos nos 60 questionários colhidos dentre os 75 questionários aplicados em uma escola da rede estadual de ensino da cidade de Queimadas-PB, com os alunos dos três anos do Ensino Médio, pois 15 pesquisados não devolveram seus questionários.

Para a análise inicial, verificou-se o quantitativo do gênero sexual dos pesquisados. A maioria dos pesquisados (53\%) são do gênero feminino, $37 \%$ do masculino e é importante salientar que $10 \%$ deles não se perceberam enquanto gêneros femininos ou masculinos.

Verifica-se que esse dado é inversamente proporcional ao encontrado para o município da pesquisa, porque há uma leve maioria do gênero masculino com $51 \%$ e o feminino com $49 \%$ da população (IBGE, 2010).

Ao serem indagados se lembravam de alguma coisa sobre o tema biodiversidade. A maioria afirmou que SIM (85\%) e NÃO (15\%).

Quando se fala em biodiversidade, em muitas regiões e localidade ainda é um componente muito importante e importante, pois faz parte da identidade cultural de muitas populações, internalizadas nas expressões usuais da fala, folclore, culinária e o artesanato, podendo ainda se fazer presente em seu ecoturismo e do turismo rural (DUARTE, 2015). 
Para Turine e Macedo (2017), valorizar da biodiversidade tem relação direta sobre é o conhecimento a respeito da mesma, em especial, sobre a sua importância, utilidade e variedade das formas de vida. Dessa forma, os componentes cognitivos e afetivos em relação aos organismos vivos são determinantes nas atitudes que as pessoas terão diante dos mesmos.

Pensando sobre um maior detalhamento sobre o tema, perguntou-se sobre o que os participantes conheciam e/ou sabiam sobre biodiversidade. O resultado mostrou que $80 \%$ dos pesquisados responderam de forma coerente, pois a principal resposta foi com relação direta à diversidade de vida/seres vivos. Parece que aqui eles expressaram o conceito inicial que os professores de ciências e biologia começam suas aulas, onde decodificam o termo BIODIVERSIDADE relacionando-o com a origem da palavra (radical Grego Bio=vida, associado a palavra diversidade=diversos) (Quadro 1).

Quadro 1. Percentual das respostas dos alunos pesquisados sobre o conceito de biodiversidade. 2018

\begin{tabular}{|c|c|}
\hline Respostas & Percentual (\%) \\
\hline Diversidade de espécies / seres vivos; & 56,7 \\
\hline Diversidade de ecossistemas; & 13,3 \\
\hline Relacionado com a ecologia; & 10 \\
\hline Muito importante; & 8,3 \\
\hline Não responderam; & 6,7 \\
\hline Outras & 5,0 \\
\hline
\end{tabular}

Segundo a Convenção sobre Diversidade Biológica (MMA, 2000), o conceito de biodiversidade é "variabilidade de organismos terrestres e aquáticos, dentre outros mais complexos, abrangendo todos os ecossistemas". Apesar de ter sido convencionado este conceito, o termo biodiversidade, já havia sido criado na segunda metade da década de 1980 e amplamente divulgado pelo eminente biólogo americano E. O. Wilson.

O desenvolvimento de uma consciência ecológica perpassa pela formação de novos sentimentos e valores em relação ao próprio ambiente natural, sendo eles refletidos em novas posturas, comportamentos e no nascer de uma relação de alteridade entre a natureza e os seres humanos (PIEPER; BEHLING; DOMINGUES, 2014).

Não se pode deixar de evidenciar que $20 \%$ dos pesquisados responderam que não lembram ou simplesmente falam que é muito importante apenas ou não responderam a questão. Tal tendência, corroborou com o estudo de Albuquerque et al. (2007) também com estudantes do Ensino Médio em outra cidade do interior paraibano.

Quanto à abordagem se tinham e em qual ano tinham foi trabalhado o assunto com eles em suas respectivas escolas, que ano, a maioria (66,7\%), respondeu que sim e $10 \%$ não responderam (Quadro 2). 
Quadro 2. Percentual das respostas dos alunos pesquisados sobre em quais séries estudaram o assunto biodiversidade. 2018

\begin{tabular}{|c|c|c|}
\hline Respostas & Séries & $\%$ \\
\hline \multirow{4}{*}{ Sim } & No $9^{\circ}$ ano & 25 \\
\hline & No $1^{\circ}$ ano do Ensino Médio & 8,3 \\
\hline & No $2^{\circ}$ ano do Ensino Médio & 16,7 \\
\hline & No $3^{\circ}$ ano do Ensino Médio & 16,7 \\
\hline \multirow{2}{*}{ Não } & Não estudaram o assunto & 16,7 \\
\hline & Não lembram em que se estudaram o assunto. & 6,6 \\
\hline Não responderam & - & 10 \\
\hline Total & Total & 100 \\
\hline
\end{tabular}

Pianovski (2009) enfatiza que o aluno constrói seu próprio conhecimento de maneira autônoma e criativa. Sendo que o papel do professor é fazer o aluno pensar e agir, além de promover novas reflexões, acompanhando os passos do educando na trajetória da construção do conhecimento.

Ao serem indagados sobre em qual o meio de comunicação eles tiveram acesso ao tema biodiversidade e que eles detalhassem em qual Programa eles assistiram, todos responderam que o único meio de comunicação que se lembravam de terem visto algum Programa foi a Televisão (canais abertos e canais pagos). (Quadro 03).

Nenhum dos pesquisados citou Programa em rádios, jornais e/ou revistas. Percebeu-se que o grupo pesquisado é expectador ativo da TV, talvez, por conta da idade do grupo pesquisado e pela maior disponibilidade de cobertura e acesso a esse meio de comunicação. Nenhum dos pesquisados abordou em suas respostas que tiveram acesso aos Programas através da internet.

Quadro 3. Percentual das respostas dos alunos pesquisados sobre em quais meios de comunicação onde viram e/ou ouviram falar sobre biodiversidade. 2018

\begin{tabular}{|c|c|c|}
\hline Respostas & Programas Citados & $\%$ \\
\hline \multirow{4}{*}{ Viram o assunto em algum meio de comunicação. } & Via Brasil, Globo Ecologia, Globo Repórter, Como Será?, & 33,4 \\
\cline { 2 - 3 } & Fantástico, Jornal Nacional & 20 \\
\cline { 2 - 3 } & Discovery Channel, Animal Planet, National Geográfic \\
\cline { 2 - 3 } & Canal Futura, Tv Escola & 8,3 \\
\cline { 2 - 3 } & SBT Repórter & 8,3 \\
\hline Viram o assunto em algum meio de comunicação & Record News & 5 \\
\hline Não responderam / não se lembram & - & 8,3 \\
\hline Total & Total & 100 \\
\hline
\end{tabular}

Para Braga (2018), os meios de comunicação como o meio de informação são essenciais para que a população possa ter uma dimensão efetiva dos problemas ambientais e que a Educação Ambiental só será mais bem trabalhada se as escolas e os meios de comunicação trabalharem no mesmo sentido.

A importância dos meios de comunicação e suas influencias nas concepções das pessoas não é uma verificação de hoje, pois Krasilchick (1996), já evidenciava isto. No entanto, é crucial que os 
professores auxiliem os alunos na análise e decodificação dessas mensagens transmitidas pelos meios de comunicação, porque a linguagem e os formatos são para atender o público em geral, com isso, as informações científicas vão ficando em segundo plano.

Estes resultados divergem de Silva Junior e Marques (2012), que verificaram que o principal canal de informação dos alunos pesquisados em Palmas-TO sobre o tema biodiversidade, foi de 44\% em mídias como TV e rádio; $30 \%$ aprenderam sobre biodiversidade na escola; $14 \%$ pela internet; $3 \%$ nos impressos e $9 \%$ em outros meios de comunicações.

Indagou-se se eles lembravam algum nome de algumas espécies da fauna e flora que estavam em extinção. Dos $85 \%$ dos pesquisados que responderam ficou evidente que detêm de algum conhecimento sobre a fauna, porém desconhecem a flora, pois só lembraram do Pau-Brasil (Quadro 04). Nesses resultados, novamente podemos destacar a influência que mídia exerce, pois os animais em extinção mais citados são os mais presentes nos Programas de televisão e até em filmes. As principais respostas foram Arara-azul (23,4\%), Mico-leão-dourado (13,3\%), e Pau-brasil (11,7\%).

Quadro 4. Percentual das respostas dos alunos pesquisados sobre a fauna e da flora em extinção. 2018.

\begin{tabular}{|c|c|c|}
\hline \multicolumn{1}{|c|}{ Respostas } & Programas Citados & $\%$ \\
\hline \multirow{4}{*}{ Conhecem espécies em extinção } & Arara-azul & 23,4 \\
\cline { 2 - 3 } & Mico-leão-dourado & 13,3 \\
\cline { 2 - 3 } & Pau-brasil & 11,7 \\
\cline { 2 - 3 } & Peixe-boi & 8,3 \\
\cline { 2 - 3 } & Urso-panda & 8,3 \\
\cline { 2 - 3 } & Tartaruga-marinha & 5 \\
\cline { 2 - 3 } & Lobo-guará & 5 \\
\cline { 2 - 3 } & Tamanduá bandeira & 3,3 \\
\cline { 2 - 3 } & Urso Polar & 1,7 \\
\cline { 2 - 3 } & Leopardo, Pantera, Rinoceronte, Leões, Tigres, Papagaios, & 5 \\
\hline Não viram nada sobre o assunto & Leão Marinho e Jacaré & 10 \\
\hline Não responderam / não se lembram & - & 100 \\
\hline Total & - & Total \\
\hline
\end{tabular}

Segundo Souza et al. (2018), a nova lista da fauna silvestre brasileira ameaçada de extinção, relaciona 1.182 espécies, porque incluíram a mais um marsupial, duas aves, cinco serpentes e um peixe troglóbio.

Também foi perguntado se a extinção de espécies, qualquer que seja, pode vir a prejudicar a manutenção da vida no planeta, especialmente a do homem e solicitou-se que os participantes justificassem a resposta. Observou-se que entre outras respostas, grande parte dos alunos (75\%) relaciona o prejuízo da perda das espécies com a sua função e importância na natureza (Quadros 5 e $6)$. 
Quadro 5. Percentual das respostas dos alunos pesquisados sobre a extinção de espécies e o que isto pode acarretar ao planeta. 2018

\begin{tabular}{|c|c|}
\hline Respostas & Percentual (\%) \\
\hline Cada espécie tem sua função (importância) & 30 \\
\hline Perda de recursos biológicos e nossa extinção & 15 \\
\hline Prejudica a cadeia alimentar (Teia Alimentar) & 13,3 \\
\hline Prejudica o ecossistema & 6,7 \\
\hline Perda de recursos biológicos & 5 \\
\hline Outras respostas & 5 \\
\hline Não & 15 \\
\hline Não responderam a questão & 10 \\
\hline
\end{tabular}

Segundo Roos (2012) o patrimônio natural da Terra é formado por plantas, animais, terra, água, a atmosfera e os seres humanos. Todos fazem parte dos ecossistemas do planeta, o que equivale dizer que, se houver uma crise de biodiversidade, a saúde e os meios de subsistência também entram em risco.

Quadro 6. Descrição das respostas dos alunos pesquisados sobre a extinção de espécies e o que isto pode acarretar ao planeta. 2018

Função e importância
"Sim, acho que cada espécie tem sua função".
"Sim, porque cada espécie de animais ou vegetais tem sua importância no planeta".
"Sim, porque os seres vivos fazem parte da Natureza e da Biodiversidade".
"Sim, por são importantes para o ciclo da vida de todos no Planeta".
Perda de recursos biológicos
"Sim, porque fazem parte de nossas vidas e a extinção deles ocasionará a nossa extinção também".
"Sim, porque todos dependemos de todos os seres para termos ar e água".
Teia Alimentar
"Sim, porque afeta e altera a cadeia alimentar".
"Sim, porque afeta toda a cadeia alimentar".
"Sim, porque todos somos essenciais à Teia Alimentar".
Ecossistema
Sim, porque vai modificar o ecossistema e todos os biomas".
"Sim, porque todas as espécies são fundamentais para o equilibrio ambiental".
Sim, porque todos são necessários para o funcionamento dos ecossistemas"
Outros
"Sim, porque se os seres vivos foram criados por Deus nós não podemos extinguir eles".
"Sim, porque aquilo que Deus criou o Homem não pode destruir, alterar ou separar.
"Acho que sim, de certa forma a humanidade poderá se prejudicar".

Conforme Guerra, Rocha e Nodari (2015), os seres humanos deveriam se importar mais a biodiversidade, porque nela se faz presente à base da saúde do planeta e tem um impacto direto sobre a vida de todos.

Foi pedido aos pesquisados que eles citassem alguns motivos pelos quais as espécies deveriam ser preservadas. Os resultados demonstram que os alunos têm certa consciência Cristã, ética e ambiental para a preservação das espécies (Quadros 7 e 8). 
Quadro 7. Percentual das respostas dos alunos pesquisados sobre os motivos da preservação das espécies. 2018

\begin{tabular}{|c|c|}
\hline Respostas & Percentual (\%) \\
\hline Motivos Religiosos & 50 \\
\hline Motivos Éticos & 25 \\
\hline Motivos Ambientais & 13,3 \\
\hline Outros Motivos & 6,7 \\
\hline Não responderam & 5 \\
\hline
\end{tabular}

Pode-se explicar a predominância dos motivos religiosos pelo fato da Conferência Nacional do Bispo do Brasil (CNBB) ter realizado em 2017 a campanha da Fraternidade tema foi "Biomas Brasileiros e a Defesa da Vida" (CNBB, 2017).

Quadro 8. Descrição das respostas dos alunos pesquisados sobre os motivos da preservação das espécies. 2018

\begin{tabular}{|c|}
\hline Motivos Religiosos \\
\hline $\begin{array}{c}\text { "Atuar contra a contra de Deus". } \\
\text { "Pecar, pois Deus criou todos os seres vivos". } \\
\text { "Porque Deus criou o mundo com todos os seres para viverem juntos", } \\
\text { "A morte dos animais só é permitida por Deus se for para se alimentar". } \\
\text { "Proteger a Natureza é Agradecer a Deus". } \\
\text { "Temos que amar os seres vivos como Deus nos ama". }\end{array}$ \\
\hline Motivos Éticos \\
\hline $\begin{array}{c}\text { "Por respeito e amor a todos os seres vivos". } \\
\text { "Por ser um ser vivo, para manter eles vivos e os pesquisadores poder estudar". } \\
\text { "Por serem essenciais a sobrevivencia da espécie humana". } \\
\text { "Porque todos ser vivo ter o direito de viver". }\end{array}$ \\
\hline Motivos Ambientais \\
\hline $\begin{array}{l}\text { "Para não ocasionar um desequilibrio ecológico" } \\
\text { "Porque o meio ambiente só existe se todos os seres existirem" } \\
\text { "Para a sobrevivência dos ambientes para as futuras gerações" } \\
\text { "Porque todos exercem um papel no equilibrio ambiental” } \\
\text { "Para a manutenção da vida e dos ecossistemas". }\end{array}$ \\
\hline Outros Motivos \\
\hline $\begin{array}{c}\text { "Porque ninguém pode matar nenhum animal e desmatar nenhuma árvore" } \\
\text { "Porque são seres vivos e não seres mortos" } \\
\text { "Porque na Lei ninguém pode matar nenhum ser vivo" } \\
\text { "Porque não somos melhor que ninguém para matar o outro". }\end{array}$ \\
\hline
\end{tabular}

Para analisar melhor as concepções dos pesquisados foi perguntando se eles achavam que os seres humanos seriam os principais responsáveis pela extinção de espécies e que explicassem suas respostas. A maioria dos pesquisados $(73 \%)$ sente-se responsáveis pela extinção das espécies, mas não demonstram de que forma poderiam agir efetivamente, contribuindo com a preservação das espécies (Figura 3). 
Figura 3. Percentual das respostas dos alunos pesquisados sobre a responsabilidade dos humanos quanto à extinção das espécies. 2018

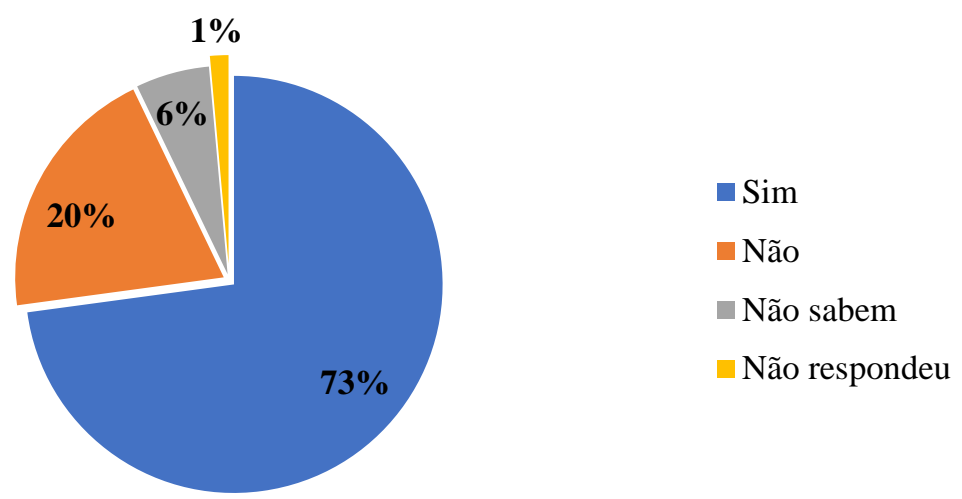

Estes resultados vão à mesma linha dos estudos de Santos e Oliveira (2017), que pesquisaram alunos do Ensino Fundamental do Pará, Brasil, e abordaram a temática biodiversidade com ênfase em conservação e extinção das espécies, onde verificaram que os alunos do sétimo ano do Ensino Fundamental de duas escolas públicas possuem baixo conhecimento sobre os assuntos relacionados à biodiversidade, demonstraram também não identificar o ser humano como um elemento constituinte da própria biodiversidade. Verificaram assim que, os conteúdos sobre Biodiversidade com ênfase em conservação e extinção das espécies devem receber uma abordagem mais integrativa com as vivências dos estudantes, e devem ser trabalhados a partir das representações e percepções deles, para que uma aprendizagem significativa possa se configurar com maior naturalidade.

Conforme Souza (2017) é tão evidente e preocupante a interferência humana sobre a natureza que ainda em 1995 o Prêmio Nobel de química foi concedido ao químico holandês, Paul Crutzen, que propôs a utilização do termo Antropoceno, para designar uma nova Era geológica, em que o sistema econômico global e o crescimento das atividades antrópicas são o principal fator responsável pela perda da biodiversidade, pela degradação dos ecossistemas e pela redução da vida selvagem no planeta.

Os impactos diretos e indiretos sobre a biodiversidade resultantes da crescente ocupação humana, além da visível degradação de ambientes naturais acomete à grande perda nos serviços ambientais, aos quais as sociedades são altamente dependentes (LAMIM-GUEDES, 2012).

Em um estudo realizado por Silva (2015) sobre a percepção dos alunos da $3^{\mathrm{a}}$ série do Ensino Médio sobre os impactos ambientais na Caatinga, em Baraúna - PB foi possível identificar nesse estudo a percepção relacionada às questões dos impactos ambientais no bioma local, as características sociais e suas potencialidades. Assim, quando questionados sobre uma contribuição para degradar o meio ambiente no município foi considerado como impacto ambiental positivo, a 
colheita de frutos, a pesca, a caça e as pastagens. Já os impactos negativos foram citados a extinção e/ou diminuição no número de espécies vegetais e animais. Contudo, não foram citados pelos pesquisados, a falta de saneamento básico, a produção de carvão, e o surgimento de novas doenças e aumento da temperatura local.

Por fim, perguntou-se aos pesquisados poderiam propor medidas eficazes para evitar a extinção das espécies e quais seriam essas medidas. Os pesquisados apresentam uma ideia confusa sobre as medidas de conservação das espécies. A maioria das respostas foi medidas de punição/fiscalização (46,7\%) (Quadro 9).

Quadro 9. Percentual das respostas dos alunos pesquisados sobre as medidas contra a extinção das espécies. 2018

\begin{tabular}{|c|c|}
\hline Respostas & Percentual (\%) \\
\hline Medidas de punição/fiscalização & 46,7 \\
\hline Educação Ambiental & 18,3 \\
\hline Proteção Ambiental & 11,7 \\
\hline Outras respostas & 8,3 \\
\hline Não responderam a questão & 5 \\
\hline Não sabem & 10 \\
\hline
\end{tabular}

De acordo com Raymundo (2015), o ambiente em que as pessoas vivem influencia a forma de pensar, de fazer e sentir. Entretanto, a Escola Formal necessita incluir em sua prática a discussão ampla de conceitos ambientais básicos, como o consumismo desenfreado, degradação ambiental, perda da biodiversidade e políticas ambientais, os grandes vilões do Meio Ambiente da atualidade, pois, sem isso, é muito complicado conscientizar e sensibilizar as pessoas que não tenham tido acesso aos conceitos considerados básicos de forma educativa numa visão mais ampla e concreta.

A escola tem um papel importante principalmente sobre o ensino de ciências na região nordestina do Brasil, a fim de propiciar aos alunos conhecimentos sobre o bioma Caatinga. Portanto, é de grande relevância a contribuição da educação ambiental para a formação de cidadãos, os quais possam repensar sobre as diferentes problemáticas de sua realidade e tenham o direito de tomar decisões e agir como indivíduos participativos (POLLI; SIGNORINI, 2012).

\section{Conclusões}

Conclui-se que as dificuldades para o ensino do tema biodiversidade se deu pelo fato dos alunos e também pelos professores darem preferência pelo conhecimento de senso-comum, o que é geralmente veiculado pelos meios de comunicações. Evidenciando uma necessidade de um maior aprofundamento no ensino formal de ciências/biologia, incentivando o pensamento crítico, com 
enfoque e maior aprofundamento nos temas biodiversidade e meio ambiente, em particular, no que diz respeito ao nosso bioma Caatinga.

Constatou-se ainda que os alunos possuem uma consciência ambiental, uma vez que consideram os humanos como os responsáveis de alguma forma pela extinção das espécies. Eles também apresentam conhecimentos poucos elaborados quando propõem medidas contra a extinção através de ações punitivas para o caminho da conservação da biodiversidade, principalmente na questão da caça irregular que é considerada por eles como a principal causa da extinção das espécies. Contudo, verificou-se que os pesquisados não demonstraram conhecimento sobre a questão da extinção de espécies da flora, e também não estabeleceram nenhuma relação da extinção com as espécies da fauna.

Em relação aos meios de comunicações onde viram ou ouviram falar sobre o tema biodiversidade observou-se que a televisão se configurou como o principal meio de divulgação do tema.

Desta forma, sugere-se que dentre os desafios para uma melhor abordagem educacional sobre o tema biodiversidade nas escolas de Queimadas-PB está à necessidade de conciliar o tema com os demais conteúdos obrigatórios da grade curricular, abordando as diversas variações locais. Portanto, o principal foco de abordagem do tema deve levar em consideração o regionalismo. Desta maneira, torna-se necessário aumentar o uso de exemplos de espécies da biodiversidade local, regional e nacional, além, de cursos de formação continuada oferecidos aos professores das ciências naturais.

\section{Referências}

ALBUQUERQUE, H.N.; BARBOSA, D.; SALES, G.P.S; ARETUSE, F. BARBOSA, A. R. Biodiversidade Animal: o que pensam os alunos do $2^{\circ}$ ano do curso de biologia de Campina Grande - Paraíba. IN. XVI ENCONTRO DE ZOOLOGIA DO NORDESTE. UFPE: GaranhunsPE. 2007.

ANDRADE, G. S.; MONTEIRO, D. E. Percepção ambiental de estudantes do Ensino Médio sobre a biodiversidade: um estudo envolvendo uma escola do Paraná. Vivências. v. 14, n.26, p.268-280, 2018.

BRAGA, W. R. O. Um estudo sobre os princípios ambientais de estudantes universitários por meio da percepção ambiental. 2018.

BRASIL, M. E. C. Orientações curriculares para o ensino médio. Ciências da natureza, matemática e suas tecnologias. Secretaria de Educação Média e Tecnológica/MEC, Brasília, 2006.

CENCI, D.; BURMANN, T. Direitos humanos, sustentabilidade ambiental, consumo e cidadania.

Revista Direitos Humanos e Democracia, v. 1, n. 2, p. 131-157. 2013. 
CNBB. Conferência Nacional do Bispo do Brasil (CNBB). Campanha da Fraternidade 2017 Biomas Brasileiros e a Defesa da Vida. 2017

DEMOLY, K. R. A.; SANTOS, J. S. B. Learning, environmental education and school: ways of enacting in the experience of students and teachers. Ambient. Soc., São Paulo, v. 21, 2018.

DINNEBIER, F. F. Estado de Direito Ecológico: Conceito, Conteúdo e Novas Dimensões para a Proteção da Natureza. São Paulo: Planeta Verde, 2017.

DUARTE, C. M. Conhecimento de estudantes do terceiro ano do ensino médio sobre biodiversidade e extinção de animais. 2015.

FISCHER, M. L. et al. Da ética ambiental à bioética ambiental: antecedentes, trajetórias e perspectivas. Hist. Cienc. Saúde - Manguinhos, Rio de Janeiro, v. 24, n. 2, p. 391-409, Apr. 2017.

GUERRA, M. P.; ROCHA, F. S.; NODARI, R. O. Biodiversidade, recursos genéticos vegetais e segurança alimentar em um cenário de ameaças e mudanças. Embrapa Cerrados. 2015.

IBGE, Instituto Brasileiro de Geografia e Estatística. Censo Demográfico. 2010. Disponível em: https://cidades.ibge.gov.br/brasil/pb/queimadas/pesquisa/23/25888?detalhes=true. Acesso em: $20 \mathrm{de}$ março de 2018.

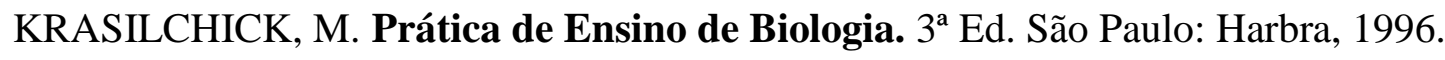

LAMIM-GUEDES, Valdir. Biodiversidade dentro da escola. Educação Ambiental em Ação, v. 39, 2012.

LINARES, S. Conocimiento profesional del profesor de matemáticas: conocimiento, creencias y contexto en relación a la noción de función. Colección Digital Eudoxus, n. 15, 2009.

MATOS, D. A. S.; JARDILINO, J. R. L. Os conceitos de concepção, percepção, representação e crença no campo educacional: similaridades, diferenças e implicações para a pesquisa. 2016.

MEDEIROS, A. B. et al. A Importância da educação ambiental na escola nas séries iniciais.

Revista Faculdade Montes Belos, v. 4, n. 1, set. 2011.

MINAYO, M. C. S. O desafio do conhecimento: pesquisa qualitativa em saúde. $14^{\mathrm{a}}$ ed. São Paulo: Hucitec; RJ: Abrasco; 2014.

MMA (MINISTÉRIO DO MEIO AMBIENTE). A Convenção sobre Diversidade Biológica CDB, DF: MMA, 2000.

MORAES, C. P. et al. Prática de campo: aprendizagem sobre biodiversidade e preservação ambiental verificada em discentes da escola estadual pirassununga, SP. Nucleus, v. 12, n. 1, p. 361370, 2015.

MORENO, M. M.; AZCÁRATE, C. Concepciones y creencias de los profesores universitarios de matemáticas acerca de la enseñanza de las ecuaciones diferenciales. Enseñanza de las Ciencias: Revista de investigación y experiencias didácticas, v. 21, n. 2, p. 265-280, 2003.

OLIVEIRA, A. P. L.; CORREIA, M. D. Ensino e Aprendizagem Através do Registro das Aulas de Campo Utilizando Diários de Bordo. Revista Brasileira De Pesquisa Em Educação Em Ciências, v. 15, n. 3, p. 537-554. 2015.

PELICIONI, A. F. Educação ambiental com estudantes percepções e práticas ambientais. In: VALDEMIR, A. R. A educação ambiental na trilha. Botucatu: Tipomic, 2000. p. 106.

PEREIRA, A. C.; DA SILVA, G. Z.; CARBONARI, M. E. E. Sustentabilidade, responsabilidade social e meio ambiente. Editora Saraiva, 2017. 
PIANOVSKI, R. R. R. Utilização de Portfólios No Estudo da Biologia Evolutiva e

Biodiversidade. Curitiba - PR: Colégio Estadual Pedro Macedo, 2009. Disponível em:

<http://www.diaadiaeducacao.pr.gov.br/portals/pde/arquivos/1679-6.pdf>. Acesso em: 12 jun 2018.

PIEPER, D. S.; BEHLING, G. M; DOMIGUES, G. Pertencimento, patrimônio e meio ambiente: Um diálogo necessário para a sustentabilidade. Revista DELOS: Desarrollo Local Sostenible, n. 21, 2014.

POLLI, A.; SIGNORINI, T. A inserção da educação ambiental na prática pedagógica. Ambiente \& Educação, Anápolis-GO, v. 17, n. 2, p. 93-101, 2012.

RATTNER, H. Meio ambiente, saúde e desenvolvimento sustentável. Ciência \& saúde coletiva, v. 14, n. 6, p. 1965-1971, 2009.

RAYMUNDO, L. S. Valores morais ambientais: a construção do sujeito ecológico. 2015.

ROOS, A. A biodiversidade e a extinção das espécies. Revista Eletrônica em Gestão, Educação e Tecnologia Ambiental, v. 7, n. 7, p. 1494-1499, 2012.

ROSSI, A. E.; MANZANO, M. A Percepção de estudantes do ensino fundamental e médio sobre o problema ambiental do Rio Xambrê, PR. Educere-Revista da Educação da UNIPAR, v. 5, n. 1, 2005.

SANTOS, T. J. S.; OLIVEIRA, G. C. S. O conhecimento de estudantes sobre biodiversidade com ênfase em conservação e extinção das espécies, Pará, Brasil. Instrumento: R. Est. Pesq. Educ., Juiz de Fora, v. 19, n. 1, jan./jun. 2017

SILVA JUNIOR, V. E.; MARQUES, E. E. A abordagem da biodiversidade no Ensino Médio de Palmas - TO. Momento, Rio Grande, v. 21, n. 1, p. 77-98, 2012.

SILVA, J. S. Impactos ambientais na caatinga: a percepção de alunos da $3^{\text {a }}$ série do Ensino Médio da Escola Estadual Prefeito Severino Pereira Gomes, município de Baraúna - PB. Monografia (Especialização em Fundamentos da Educação: Práticas Pedagógicas Interdisciplinares) - Universidade Estadual da Paraíba, Cuité, 2015.

SÖNCKSEN, B. M. A conservação da biodiversidade segundo alunos do curso de ciências biológicas. 2017.

SOUZA, Rafael Speck de et al. Direito animal à luz do pensamento sistêmico-complexo: um enfoque integrador da crise socioambiental a partir da constituição federal de 1988. 2017.

SOUZA, E. C. F; BRANT. A; RANGEL, C. A.; BARBOSA, L. E.; CARVALHO, C. E. G.; JORGE, R. S. P.; SUBIRÁ, R. J. Avaliação do risco de extinção da fauna brasileira: ponto de partida para a conservação da biodiversidade. Diversidade e Gestão. v. 2, n. 2, p. 62-75. 2018.

TRIVIÑOS, A. N. S. Introdução à pesquisa em ciências sociais: a pesquisa qualitativa em Educação. 5. ed. repreim. São Paulo: Atlas, 2009.

TURINE, J. A. V.; MACEDO, M. L. R. Direitos Humanos, Comunidades tradicionais e Biodiversidade: Desafios para o desenvolvimento sustentável. Revista Direito UFMS, v. 3, n. 2, 2017. 